\title{
Exercise-induced hyperphagia in the hamster is associated with elevated plasma somatostatin-like immunoreactivity
}

\author{
B. Shapiro ${ }^{1}$, K.T. Borer ${ }^{2}$, L.M. Fig ${ }^{1}$ and A.I. Vinik ${ }^{1}$ \\ Departments of ${ }^{1}$ Internal Medicine and ${ }^{2}$ Kinesiology, The University of Michigan, Ann Arbor, MI, U.S.A.
}

(Received 5 December 1986; revised version received 18 February 1987; accepted 26 February 1987)

\section{Summary}

Syrian golden hamsters when allowed free access to food and an exercise wheel will run long distances and develop hyperphagia and accelerated linear body growth with high circulating levels of growth hormone and insulin. Somatostatin, a widely distributed brain-gut neurohormonal peptide, modulates nutrient absorption and may regulate food intake. To examine the role of circulating plasma somatostatinlike immunoreactivity (SRIF-LI; $\mathrm{pg} / \mathrm{ml}$ ) in exercise induced hyperphagia 4 groups of animals were studied; an unrestricted exercise group (279.0 $\pm 107.7, n=10)$; a sedentary group $(121.1 \pm 40.8, n=8)$; a restricted exercise group $(107.7 \pm 12.4, n$ $=6)$; and a restricted no exercise group $(115.5 \pm 45.9, n=9)$. Thus, the unrestricted exercise group has a significantly elevated SRIF-LI concentration $(P<0.01)$ while there was no difference between the other 3 groups. The elevation of plasma SRIF$\mathrm{LI}$ in the unrestricted exercise group may represent a response to modulate increased nutrient entry in this group or may represent an incompletely effective satiety signal.

Hyperphagia; Accelerated growth; Somatostatin

\section{Introduction}

Syrian golden hamsters, allowed free access to food and an exercise wheel, will run long distances at night which induces a syndrome of hyperphagia and accelerated

Correspondence: A.I. Vinik, Division of Endocrinology and Metabolism, University of Michigan Medical Center, 2922 B Taubman Health Center, Ann Arbor, MI 48109/0331, U.S.A. 
linear body growth [1]. These hyperphagic growing animals have high circulating levels of growth hormone due to increases in pulse frequency and amplitude [2] and of insulin [1] which may mediate the accelerated linear growth. When exercising with restricted access to food, linear growth [1] and cellular proliferation of the distal femoral epiphyseal growth zone is blocked [3].

Somatostatin (somatotrophin release inhibiting factor, SRIF), was initially extracted from the hypothalamus and acts within the hypothalamic-pituitary portal venous system as a true hormonal regulator of growth hormone secretion [4,5]. It has since been found to have a far wider tissue distribution and probably serves multiple functions [6,7]. These include: (a) presence in neurons of many areas of the brain, spinal cord and peripheral nervous system where it is a putative peptidergic neurotransmitter/neuromodulator $[6,8]$; b: widespread distribution throughout the gut $[6,8]$ where it is distributed in the intrinsic autonomic neurons and in mucosal endocrine cells $[6,8]$, where it is believed to act as a paracrine transmitter and, within the visceral portal system, as a hormone $[9,10]$. SRIF's actions on the gut include suppression of many gut hormones including gastrin, secretin and CCK; reduction of gastric secretion, reduction in pancreatic-exocrine secretion, reduced gut motility, and delayed nutrient absorption [5,11-14]; c: within the pancreas the majority of SRIF is present in the $\delta$ cells of the islets $[6,8]$ where it appears to act as a paracrine transmitter or to transmit a signal by intimate cell-to-cell contact via tight junctions. Its action here is to reduce insulin and glucagon secretion [12]. It also enters the portal system where it may act as a hormone $[9,10,15]$.

We examined somatostatin-like immunoreactivity (SRIF-LI) in the general circulation of exercising hyperphagic animals and appropriate controls to test the hypothesis that this state with its striking alteration in nutrient ingestion, growth and activity, may be associated with alterations in circulating SRIF-LI.

\section{Materials and Methods}

Female golden hamsters (Mesocricetus auratus Waterhouse) over 10 weeks old and weighing 90-100 g (Eagle Laboratory Animals, Farmersburg, IN) were individually housed under conditions of constant temperature $\left(22^{\circ} \mathrm{C}\right.$ and a $12 \mathrm{~h}$ light/dark cycle with continuous access to tap water ad lib. Animals were divided into 4 experimental groups of $10[1,3]$ :

(a) Unrestricted exercise group. Animals were allowed free access to an unlimited supply of Purina Chow Formulab 5008 and to a horizontal exercise wheel.

(b) Sedentary group. Animals were allowed free access to unlimited supply of Purina Chow Formulab 5008 without an exercise wheel.

(c) Restricted exercise group. Animals were allowed free access to an exercise wheel but food intake was restricted to the quantity consumed by the sedentary group.

(d) Restricted no exercise group. Animals were not allowed access to the exercise wheel and food intake was restricted to a point where no weight gain occurs.

The disk exerciser was a freely turning perspex disk $23-25 \mathrm{~cm}$ in diameter, the revolutions of which could be electrically recorded $[1,3]$. 
Animals were weighed daily and the ponderal growth calculated for the experimental period. Animals were sacrificed in random order by decapitation during the second hour of the daylight cycle. Trunk blood was collected into chilled glass tubes containing Trasylol (aprotinin $5000 \mathrm{KIU} / \mathrm{ml}$ ) and EDTA to yield a 10:1 ratio $(4 \mathrm{ml}$ of blood). The plasma was immediately separated by centrifugation and stored in aliquots at $-20^{\circ} \mathrm{C}$ until assay.

Somatostatin-like immunoreactivity (SRIF-LI) was determined in unextracted plasma by a radioimmunoassay using an antiserum (Cape Town 1374) raised in a rabbit to synthetic cyclic SRIF-(1-14) conjugated to whelk hemocyanin by the carbodiimide reaction [16-18]. The antiserum has been shown to be specific for the 611 region of SRIF-14. It has $75 \%$ cross-reactivity with SRIF-(1-25) and a $60 \%$ cross-reactivity with SRIF-(1-28) [18]. [Tyr $\left.{ }^{1}\right]$ SRIF was radiolabeled by the chloramine- $\mathrm{T}$ technique with ${ }^{125}$ iodine and the tracer was purified by ion exchange chromatography on CM- 52 cellulose to a specific activity of ca. $750 \mathrm{Ci} / \mathrm{mol}$. The standard was synthetic cyclic somatostatin-(1-14) (Ayerst AY 24910, Ayerst Laboratories, Rouses Point, NY). The assay was performed in $50 \mathrm{mM}$ ammonium acetate buffer at a $\mathrm{pH}$ of 5.6 [19]. This low $\mathrm{pH}$ has been shown to permit the assay of SRIF-LI in rat [10] and human [16] plasma without extraction. Separation of antibody-bound from unbound tracer was achieved by the use of dextran-coated charcoal. The limit of sensitivity ( 2 standard deviations above assay buffer control tubes) was $2 \mathrm{pg} /$ tube. The intra-assay coefficient of variation was $5 \%$ and the interassay coefficient of variation was $12 \%$.

Plasma samples were assayed in triplicate in 3 dilutions to determine parallelism of plasma SRIF-LI with the standard curve. Recovery of standard somatostatin from plasma was determined by the addition of $500 \mathrm{ng} / \mathrm{ml}$ of synthetic cyclic SRIF-(1-14) to aliquots of hamster plasma and serially diluting with SRIF-free plasma. Nonspecific binding of the ${ }^{125}{ }^{5}-\left[\mathrm{Tyr}^{1}\right] \mathrm{SRIF}$ with hamster plasma resulted in no more than $5 \%$ damage to the label as determined by chromatoelectrophoresis. Plasma SRIF-LI concentrations were expressed as pg SRIF-(1-14) equivalents/ml.

\section{Statistical methods}

Overall differences between the 4 groups were determined using the Welch statistic for one-way analysis of variance. Multiple pairwise comparisons to determine significance at the $P=0.01$ level were made using the Bonneferroni correction method [20].

\section{Results}

The mean body weights for the 10 animals in each experimental group are shown in Fig. 1 which shows that the exercising group had the typical accelerated growth when compared to the sedentary controls while the exercising restricted and sedentary restricted groups showed minimal growth.

The mean plasma SRIF-LI concentrations for all 4 groups of animals are presented in Table I. The exercised group of animals with free access to food had a highly 


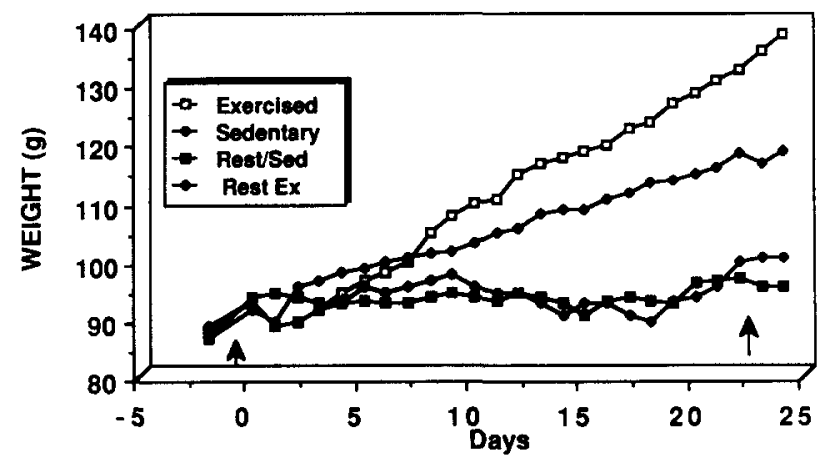

Fig. 1. Changes in weight in the 4 groups of hamsters. The first arrow indicates the start of the experiment and the second arrow the time of sacrifice. Rest, food-restricted; Sed, sedentary; Ex, exercise.

\section{TABLE I}

Plasma-SRIF-LI concentrations in the 4 groups of animals (individual data) $\mathrm{pg} / \mathrm{ml}$

\begin{tabular}{llllr}
\hline $\begin{array}{l}\text { Unrestricted } \\
\text { exercise }\end{array}$ & $\begin{array}{l}\text { Unrestricted } \\
\text { sedentary }\end{array}$ & $\begin{array}{c}\text { Restricted } \\
\text { exercise }\end{array}$ & $\begin{array}{l}\text { Restricted } \\
\text { sedentary }\end{array}$ \\
& 302.9 & 179.7 & 92.4 & 178.8 \\
& 500.5 & 155.4 & 121.6 & 78.0 \\
& 312.9 & 138.1 & 91.8 & 183.0 \\
& 161.5 & 120.7 & 109.7 & 112.4 \\
& 304.9 & 137.1 & 119.3 & 43.9 \\
& 164.5 & 52.4 & 111.4 & 106.2 \\
& 346.2 & 102.3 & & 129.7 \\
Mean (pg/ml) & 216.1 & 83.7 & & 127.5 \\
\pm S.D. & 155.1 & & 19.7 \\
Mean weight (g) & 325.5 & $121.2^{* *}$ & $107.7^{* *}$ & $115.5^{* *}$ \\
& $279.0^{*}$ & \pm 40.8 & \pm 12.4 & \pm 45.9 \\
\hline
\end{tabular}

* Unrestricted exercise greater than all 3 other groups, $P<0.01$.

** No significant differences between unrestricted sedentary restricted exercise and restricted sedentary groups.

significant $(P<0.01)$ elevation of plasma SRIF-LI when compared to be sedentary groups and exercising food-restricted hamsters. Plasma SRIF-LI in the latter 3 groups did not differ significantly. (The $F$-value for the overall main effect was 13.54.)

\section{Discussion}

If adult golden hamsters in the slow asymptotic phase of growth are given the opportunity to exercise on horizontal exercise disks, they voluntarily engage in high levels of physical activity and re-enter the exponential phase of linear and ponderal 
growth throughout their exposure to such exercise. The linear growth is possible as the epiphyseal growth plates remain open in adulthood. This phenomenon is associated with marked hyperphagia and the growth may be inhibited entirely by restricting nutrient intake to the level of sedentary controls [1]. The exercise induced hyperphagia is associated with increased circulating levels of growth hormone and insulin [1] which may act, probably through the mediation of somatomedin, to induce accelerated growth. Increases in circulating growth hormone (GH) are a consequence of a doubling of GH pulse frequencies and amplitude [2]. Exercise-induced facilitation of pulsatile $\mathrm{GH}$ release is mediated by release of endogenous opiates which appear to restrain the action of endogenous somatostatin [2]. Which may have been increased in parallel with peripheral blood SRIF-LI.

The ingestion of an increased amount of food in the exercising animals is associated with a striking elevation in the plasma SRIF-LI levels. Exogenously administered SRIF reduces gastrin levels, gastric acid and enzyme output, delays gastric emptying, reduces pancreatic exocrine secretion, reduces gastrointestinal motility and slows nutrient absorption [5,11-14]. SRIF also decreases pancreatic endocrine secretion of insulin and glucagon [12] and gut peptide secretion [12,14]. These effects, coupled with the fact that nutrient ingestion releases gastrointestinal $[15,21,22]$ and pancreatic endogenous SRIF-LI [15,22] has led to the postulate that SRIF-LI acts physiologically to modulate and slow the absorption of nutrients from the gut and modulates the hormonal response to absorbed nutrients [16,17,23-25].

The source of the elevated SRIF-LI in the general circulation of the exercising animals is probably the gut and pancreas which is the site of the largest proportion of SRIF [6-9,18,36] containing tissues and furthermore is a site from which nutrients are known to cause such release $[15,17,19,22-25]$. The assay utilized measures of SRIF-(1-14) as well as SRIF-(1-25) but the relative proportions of the various subforms of SRIF-LI $[17,26]$ was not further investigated. The SRIF-LI concentrations measured in unextracted plasma by this assay $[10,19,34]$ are higher by a factor of 3 or greater than in techniques utilizing extraction $[21,23,24,33]$. Nevertheless, the relative concentration in different parts of the circulation and the responses to nutritional and other stimuli are consonant with the findings of others using extraction $[10,19,21,23,24,26,37]$.

The hypothalamic pituitary portal SRIF is unlikely to contribute to the marked increase in SRIF-LI in the general circulation as the degree of dilution of hypothalamic portal blood has been shown to preclude this $[9,19]$. In addition, the elevated growth hormone levels with evidence that in exercising animals endogenous opiates restrain endogenous somatostatin action on $\mathrm{GH}$ release [2] militate against inhibition by this component of circulating SRIF-LI. These concentrations of SRIF-LI are similar to those occurring following meal ingestion in man and other animals [15$17,22,37]$ and are of a magnitude which has been shown when infused exogenously to reduce nutrient absorption and pancreatic exocrine function [1,5,11-14].

Nutrient ingestion is a major stimulus to SRIF-LI secretion and somatostatin is believed to regulate or modulate nutrient absorption from the gut $[22,23,25,35]$. In the exercise induced hyperphagic state, increased food ingestion might provide an exaggerated stimulus and thus may explain the striking increase in circulating SRIF. 
LI $[22,23,25]$. Once amino acids and other nutrients are absorbed these also act as a stimulus to SRIF-LI release from the pancreas and gut [15,19,21,23-25]. In addition somatostatin has been shown to induce satiety and thus may serve to modulate nutrient ingestion $[29,30,32]$ in a negative feedback loop. The exercise induced hyperphagia may thus activate counter-regulatory SRIF-LI secretion to modulate the nutrient ingestion (albeit that this satiety signal is at best only modestly effective as evidenced by the ongoing hyperphagia). To determine if the elevated circulatory SRIFLI levels are the consequence of exercise (by means of the hyperphagia it induces) or to the hyperphagia per se it would be necessary to examine SRIF-LI levels in other hyperphagic models, such as the gold thioglucose mouse, the Zucker rat or, the $\mathrm{Ob}$ Ob mouse.

In man [27] and in the horse [28] vigorous exercise has been shown to elevate circulating somatostatin levels, by an, as yet, unknown mechanism. Our experiences would seem to indicate that exercise per se is not responsible for the elevation of plasma SRIF-LI in the hamster since SRIF-LI did not rise in exercised food restricted animals unless restriction of food intake is capable of suppressing exercise induced SRIF-LI secretion. Fasting and starvation do reduce circulating SRIF-LI levels in the rat $[10]$.

In conclusion, we thus believe these studies have demonstrated that the exerciseinduced hyperphagia observed in hamsters is associated with the hyperinsulinemia, hypersomatotropinemia and elevation of circulating SRIF-LI which serves to modulate the increased nutrient entry in this state.

\section{Acknowledgements}

This work was supported, in part, by the National Science Foundation Grants PCM 78-07626 and PCM 81-06375 to K.T. Borer and NIH Grant AM 27077 and a grant from the Kroc Foundation to A.I. Vinik. We thank Lois Wagner, Joyce Blemly and Lynde Amstutz for skilled technical assistance and for manuscript preparation.

\section{References}

1 Borer, K.T. and Kelch, R.P., Increased growth hormone and somatic growth in exercising adult hamsters, Am. J. Physiol., 234 (1978) E611-E616.

2 Borer, K.T., Nicoski, D.R. and Owens, V., Alteration of pulsatile growth hormone secretion by growth-inducing exercise: involvement of endogenous opiates and somatostatin, Endocrinology, 118 (1986) 844-850.

3 Borer, K.T., Raymond, P. and Dokas, L.P., Neuroendocrine effects. In K.T. Borer, D.W. Edington and T.P. Waite, (Eds.), Frontiers of Exercise Biology, Human Kinetics, 1983, pp. 263-283.

4 Brazeau, P., Vale, W., Burgus, R. et al., Hypothalamic peptide that inhibits the secretion of immunoreactive pituitary growth hormone, Science, 179 (1973) 77.

5 Schusdziarra, V., Rouiller, A., Arimura, A. et al., Anti-somatostatin serum increases levels of hormones from the pituitary and the gut, but not from the pancreas, Endocrinology, 103 (1978) 19561959. 
6 Hokfelt, T., Efendic, S., Hellerstrom, C. et al., Cellular localization of somatostatin endocrine-like cells and neurones of the rat with special references to the $A_{1}$ cells of the pancreas and to the hypothalamus, Acta Endocrinol., (Suppl), 200 (1975) 5.

7 Kronhein, S., Berelowitz, M. and Pimstone, B.L., A radioimmunoassay for growth hormone releaseinhibiting hormone: method and quantitative tissue distribution, Clin. Endocrinol., 5 (1976) 619.

8 Vale, W., Ling, N., Rivier, J. et al., Anatomic and phylogenetic distribution of somatostatin, Metabolism, 25, Suppl. 1 (1976) 1491.

9 Zyznar, E.S., Pietri, A.O., Harris, V. et al., Evidence for the homonal status of somatostatin in man, Diabetes, 30 (1981) 883.

10 Shapiro, B., Berelowitz, M., Pimstone, B.L. et al., Tissue and serum somatostatin-like immuno-reactivity in fed, 15h-fasted and 72h fasted rats, Diabetes, 28 (1979) 182.

11 Johansson, C., Wisen, O., Efendic, S. et al., Effects of somatostatin on gastrointestinal propagation and absorption of oral glucose in man, Digestion, 22 (1981) 126.

12 Adrian, T.E., Barnes, A.J., Long, R.G. et al., The effect of somatostatin analogs on secretion of growth, pancreatic and gastrointestinal hormones in man, J. Clin. Endocrinol. Metab., 53 (1981) 675.

13 Bloom, S.R., Mortimer, C.M., Thorner, M.O. et al., Inhibition of gastrin and gastric acid secretion by growth hormone release inhibiting hormone, Lancet, 2 (1976) 1106-1109.

14 Boden, G., Sivitz, M.C., Owen, O.E. et al., Somatostatin suppresses secretin and pancreatic exocrine secretion, Science, 190 (1975) 163-165.

15 Schusdziarra, V., Rouiller, D., Pietri, A. et al., Pancreatic and gastric release of somatostatin-like immunoreactivity during intestinal phase of a meal, Am. J. Physiol., 237 (1979) E555-E560.

16 Vinik, A.I., Levitt, N.S., Pimstone, B.L. et al., Peripheral plasma somatostatin-like immunoreactive responses to insulin hypoglycemia and a mixed meal in healthy subjects and in non-insulin-dependent maturity-onset diabetics, J. Clin. Endocrinol. Metab., 52 (1979) 330-337.

17 Vinik, A.I., Gaginella, T.S., O'Dorisio, T.M. et al., The distribution and characterization of somatostatin-like immunoreactivity in epithelial cells, submucosa and muscle of the rat stomach and intestine, Endocrinology, 109 (1981) 1921-1926.

18 Borer, K., Shapiro, B. and Vinik, A.I., A role for somatostatin in the control of hamster growth, Brain Res Bull., 11 (1983) 663-669.

19 Berelowitz, M., Kronheim, S., Pimstone, B. et al., Somatostatin-like immunoreactivity in rat blood. Characterization, regional differences and responses to oral and intra-venous glucose, J. Clin. Invest., 61 (1978) 1410-1414.

20 Miller, R.G., Simultaneous Statistical Reference. McGraw Hill, New York, 1980, 109-128.

21 Lucey, M.R., Fairclough, P.D., Wass, J.A.H., et al., Response of circulatory somatostatin, GIP, insulin and gastrin to intra-duodenal infusion of nutrients in normal man, Clin. Endocrinol., 21 (1986) 209-217.

22 Schusdziarra, V., Rouiller, D., Harris, V. et al., Gastric and pancreatic release of somatostatin-like immunoreactivity during the gastric phase of a meal; effects of truncal vagotomy and atropine in the anaesthetized dog, Diabetes, 28 (1979) 658-663.

23 Penman, E., Wass, J.A.H., Medbak, S. et al., Responses of circulating immunoreactive somatostatin to nutritional stimuli in normal subjects, Gastroenterology, 81 (1981) 692-699.

24 Wass, J.A.H., Penman, E., Dryburgh, J.R. et al., Circulating somatostatin after food and glucose in man, Clin. Endocrinol., 12 (1980) 569.

25 Schusdziarra, V., Zyznar, E., Rouiller, D. et al., Splanchnic somatostatin; a hormonal regulator of nutrient homeostasis, Science, 207 (1980) 530.

26 Patel, Y.C., Wheatley, T. and Ling, C., Multiple forms of immunoreactive somatostatin: comparison of distribution in neural and non-neural tissues and portal plasma of the rat, Endocrinology, 109 (1981) 1963-1969.

27 Hilsted, J., Galbo, H., Sonne, T. et al., Gastroenteropancreatic hormonal changes during exercise. Am. J. Physiol., 239 (1980) G136-G160.

28 Hall, G.M., Adrian, T.E. and Bloom, S.R., Changes in circulating gut hormones in the horse during long distance exercise, Equine Vet. J., 14 (1982) 209-212.

29 Lotter, E.C., Krinsky, R., McKay, J.M. et al., Somatostatin decreases food intake of rats and baboons, J. Comp. Physiol. Psychol., 95 (1981) 278-287. 
30 Smith, G. P. and Gibbs. J,, Gut peptides and postprandial satiety, Fed Proc. Fed. Am. Soc. Exp. Biol., 43 (1984) $2889-2829$.

31 Vijayan, E. and McCann, S.M., Suppression of feeding and drinking activity in rats following intraventricular injection of thyrotropin releasing hormone (TRH), Endocrinology, 100 (1977) 1727-1730.

32 Levine, A.S. and Morley, J.E., Peripherally administered somatostatin reduces feeding by a vagal mediated mechanism, Pharmacol. Biochem. Behav., 16 (1982) 897-902.

33 Arimura, A., Sato, H., Dupoint, A. et al., Somatostatin: an abundance of immunoreactive hormone in rat stomach and pancreas, Science, 189 (1975) 1007.

34 Jaspan, J., Polonsky, K., Lewis, M. et al., Reduction in portal vein blood flow by somatostatin, Diabetes, 28 (1979) 888-892.

35 Lucey, M.R., Wass, J.A.H., Fairclough, P. et al., Autonomic regulation of postprandial plasma somatostatin, gastrin, insulin, Gut, 26 (1985) 683-688.

36 Luft, R., Efendic, S., Hokfelt, T. et al., Immunohistochemical evidence for the localization of somatostatin-like immunoreactivity in a cell population of the pancreatic islets, Med. Biol., 52 (1976) 428.

37 Pimstone, B., Berelowitz, M., Kranold, D. et al., Somatostatin-like immunoreactivity (SRIF-LI) in human and rat serum, Metabolism, 27, Suppl. 1, 1978, 1145.

38 Wass, J.A.H., Somatostatin, its physiology in man in health and disease. In G.M. Besser (ed.), Clinical Neuroendocrinology, Vol. 11, Academic, London, 1982, pp. 359-395. 